\title{
KOMPOSISI JENIS DAN KEPADATAN BIVALVIA DIPERAIRAN PANTAI DUSUN TANJUNG METIELLA NEGERI LIANG KECAMATAN SALAHUTU
}

\author{
Aneke Latuihamallo \\ Program Studi Pendidikan Biologi \\ E-mail: aneke_latuihamallo@yahoo.com
}

\begin{abstract}
Background: Ecologically, marine waters are divided into several zones, one of which is intertidal waters, where various types have adapted well to habitat conditions in various zones and types of ecosystems. The existence of bivalves plays an important role in the lives of fish and other biota that are bound to one food chain.

Method: This research is a descriptive research that is to express descriptive information about bivalves in the waters of Metiella Cape. This study uses data collection techniques using the line transect method where each observation transect is drawn by a rope perpendicular to the coastline of 5 transects with a distance between each transect of 20 meters. As long as the transect is made of sample plots or quadrants with an area of $1 \mathrm{mX} 1 \mathrm{~m}$ with a distance between each of the 5 meter quadrants, observation of the type of bivalvia is carried out in each quadrant.

Results: The composition of Bivalvia found in Metiella Cape waters is 282 individuals classified in 2 sub-orders, 5 super families, 5 families, 7 genera, 8 species, namely: Pinna muricatta, Trachycardium rugosum, Fragum unedo, Mactra violacea, Tellina spengleri, Tellina timorensis, Gafrarium tumidum, Meretrix linnaeus.

Conclusion: In the waters of Metiella Cape, 8 types of Bivalvia were found, namely: Fragum unedo, Trachycardium rugosum, Mactra violacea, Tellina spengleri, Tellina timorensis, Pinna muricata, Gafrarium tumidum and Meretrix linnaeus. The highest density value is found in transect II with a density value of 5.8 ind / $\mathrm{m} 2$ found in the type of Fredoum unedo and the lowest density value found on transect III with a density value of 0.2 ind / $\mathrm{m} 2$ found in Mactra violacea.
\end{abstract}

Keywords: Type composition, density, bivalves

\begin{abstract}
Abstrak
Latar Belakang: Secara ekologis, perairan laut dibagi menjadi beberapa zonasi, salah satunya adalah perairan intertidal, dimana berbagai jenis telah beradaptasi dengan baik terhadap kondisi habitat di berbagai zona maupun tipe ekosistem tersebut. Keberadaan bivalvia sangat berperan dalam kehidupan ikan dan biota lainnya yang terikat pada satu mata rantai makanan.

Metode: Penelitian ini merupakan penelitian deskriptif yaitu mengungkapkan informasi secara deskriktif tentang bivalvia yang ada di perairan Dusun Tanjung Metiella. Penelitian ini menggunakan teknik pengumpulan data dengan menggunakan metode line transek dimana setiap transek pengamatan ditarik tali tegak lurus dengan garis pantai tersebut sebanyak 5 transek dengan jarak antara setiap transek 20 meter. Sepanjang transek dibuat petak sampel atau kuadran dengan luas 1 $\mathrm{m} \times 1 \mathrm{~m}$ dengan jarak antara masing-masing kuadran 5 meter, pengamatan jenis bivalvia dilakukan pada setiap kuadran.

Hasil: Komposisi jenis Bivalvia yang ditemukan pada perairan Dusun Tanjung Metiella adalah sebanyak 282 individu yang digolongkan dalam 2 sub ordo, 5 super family, 5 family, 7 genus, 8 species yaitu: Pinna muricatta, Trachycardium rugosum, Fragum unedo, Mactra violacea, Tellina spengleri, Tellina timorensis, Gafrarium tumidum, Meretrix linnaeus.

Kesimpulan: Pada perairan Dusun Tanjung Metiella ditemukan 8 jenis Bivalvia yaitu: Fragum unedo, trachycardium rugosum, Mactra violacea, Tellina spengleri, Tellina timorensis, Pinna muricata, Gafrarium tumidum dan Meretrix linnaeus. Nilai kepadatan tertinggi terdapat pada transek II dengan nilai kepadatan sebesar $5,8 \mathrm{ind} / \mathrm{m}^{2}$ ditemukan pada jenis Fragum unedo dan nilai kepadatan terendah terdapat pada transek III dengan nilai kepadatan sebesar $0,2 \mathrm{ind} / \mathrm{m}^{2}$ ditemukan pada Mactra violacea.
\end{abstract}

Kata Kunci: Komposisi jenis, Kepadatan, Bivalvia 


\section{PENDAHULUAN}

Provinsi Maluku merupakan salah satu Provinsi Kepulauan di Indonesia dengan jumlah pulau sebanyak 559 buah, memiliki Wilayah seluas $12.479 .69 \mathrm{~km}^{2}$ yang terdiri dari daratan seluas \pm 54.185 $\mathrm{km}^{2}$ atau $7,6 \%$ dan lautan seluas \pm $658.294 .69 \mathrm{~km}^{2}$ atau 92,4\% (Provinsi Maluku, 2001 dalam Latumeten, 2003). Berdasarkan luas lautan yang begitu besar, maka salah satu perhatian khusus Pemerintah Daerah dalam bidang Perikanan adalah hasil laut yang sangat melimpah, yang apabila dimanfaatkan dengan baik maka dapat meningkatkan kesejahteraan masyarakat. Mengingat hal tersebut maka wajar apabila lautan merupakan suatu sumber daya yang sangat penting bagi kehidupan masyarakat didaerah ini, bila dikelola dan dikembangkan terutama dalam mencari sumber-sumber pangan baru. Hal ini sesuai dengan apa yang dikemukakan oleh Nybakken,(1992) bahwa laut merupakan wilayah yang cukup luas serta didalamnya terkandung berbagai jenis organisme yang sangat potensial untuk dikembangkan.

Secara ekologis, perairan laut dibagi menjadi beberapa zonasi, salah satunya adalah perairan intertidal, dimana berbagai jenis telah beradaptasi dengan baik terhadap kondisi habitat diberbagai zona maupun tipe ekosistem tersebut. Berdasarkan kondisi lingkungan daerah intertidal terbagi atas zona intertidal berbatu dan zona intertidal berpasir (Nybakken, 1988). Lebih lanjut dijelaskan bahwa bermacam-macam invertebrata yang hidup secara bentos didaerah intertidal mempunyai kisaran ukuran yang sangat luas yaitu berukuran mikro seperti protozoa sampai ukuran makro seperti crustacea dan mollusca. Bivalvia merupakan salah satu ordo dari filum moluska yang merupakan biota asosiasi di daerah intertidal, artinya bahwa organisme ini sering dijumpai pada daerah intertidal.

Keberadaan bivalvia sangat berperan dalam kehidupan ikan dan biota lainnya yang terikat pada satu mata rantai makanan. Dibanding dengan manfaat hasil laut lainnya, pemanfaatan bivalvia di Indonesia terbatas pada segi komoditas maupun daerahnya. Walaupun sudah ada usaha budidaya beberapa jenis bivalvia, tetapi secara umum konsumsi bivalvia yang ada sekarang masih berasal dari pengambilan di alam. Proses pengambilan di alam yang bertujuan untuk memenuhi kebutuhan manusia, menyebabkan terjadinya over eksploitasi sumber daya bivalvia untuk konsumsi. Over eksploitasi menyebabkan sumber daya hayati laut khususnya bivalvia semakin berkurang dan mulai sulit ditemukan pada daerah tersebut. Perairan Dusun Tanjung Metiella Negeri Liang Kecamatan Salahutu Kabupaten Maluku Tengah merupakan salah satu bagian dari daerah pesisir pantai yang ada di Maluku yang juga merupakan perairan yang produktif dilihat dari faktor fisika kimia air lautnya, yang menyimpan berbagai biota laut yang salah satunya adalah bivalvia. Oleh masyarakat setempat bivalvia ini biasa dimanfaatkan untuk dikonsumsi menggantikan ikan. Selain dagingnya dimakan juga dijadikan sebagai sumber mata pencaharian dan pendapatan untuk memenuhi kebutuhan ekonomi. Bila pemanfaatnya berlebihan dan tidak mempertimbangkan kelestarian sumber daya dan lingkungan, maka dikhawatirkan potensi sumber daya bivalvia akan berkurang dan tidak mustahil pada suatu saat akan punah.

\section{MATERI DAN METODE Tipe penelitian}

Penelitian ini merupakan penelitian deskriptif yaitu mengungkapkan informasi secara deskriktif tentang bivalvia yang ada di perairan Dusun Tanjung Metiella.

\section{Waktu dan Tempat Penelitian}

Penelitian ini telah dilaksanakan pada akhir Juli 2016, bertempat di perairan Dusun Tanjung Metiella, Negeri Liang Kecamatan Salahutu Kabupaten Maluku Tengah.

\section{Populasi dan Sampel}

Populasi dalam penelitian ini adalah seluruh bivalvia yang ada di perairan Dusun Tanjung Metiella, Negeri Liang Kecamatan Salahutu Kabupaten Maluku Tengah. Sampel dalam penelitian ini adalah seluruh bivalvia yang ada di dalam plot pengamatan di perairan Dusun Tanjung Metiella, Negeri 
Liang Kecamatan Salahutu Kabupaten Maluku Tengah.

\section{Teknik Pengumpulan Data}

Teknik pengumpulan data yang digunakan dalam penelitian ini adalah pengumpulan data dengan menggunakan metode line transek (Fachrul, 2007). Dimana setiap transek pengamatan ditarik tali tegak lurus dengan garis pantai tersebut sebanyak 5 transek dengan jarak antara setiap transek 20 meter. Sepanjang transek dibuat petak sampel atau kuadran dengan luas $1 \times 1 \mathrm{~m}$ dengan jarak antara masingmasing kuadran 5 meter,

\section{Teknik Analisis Data}

Untuk mengetahui komposisi jenis maka dibandingkan antara jumlah masing masing jenis dengan total individu seluruh jenis, yang dimodifikasi dari Fachrul (2012):

$$
\text { Kj } \frac{n i}{N} \times 100 \%
$$

Dimana:

$\mathrm{Kj}=$ Komposisi jenis Bivalvia (\%)

$\mathrm{Ni}$ = Jumlah individu setiap jenis bivalvia

$\mathrm{N}=$ Jumlah individu seluruh jenis bivalvia

Kepadatan bivalvia dihitung dengan menggunakan rumus dari (Brower, et al.1990 dalam Emiyarti, dkk, 2013).

$$
\text { Kepadatan }=\frac{\text { Jumlah individu suatu spesies }}{\text { Luas area pengamatan }\left(\mathrm{m}^{2}\right)}
$$

\section{HASIL DAN PEMBAHASAN}

Komposisi jenis Bivalvia yang ditemukan pada perairan Tanjung Metiella adalah sebanyak 282 individu yang digolongkan dalam 2 sub ordo, 5 super family, 5 family, 7 genus, 8 spesies, dapat dilihat pada tabel 2 .

Tabel 2. Komposisi Jenis Bivalvia Pada Perairan Tanjung Metiella

\begin{tabular}{lllll}
\hline \multicolumn{1}{c}{ Ordo } & $\begin{array}{c}\text { Super } \\
\text { Family }\end{array}$ & \multicolumn{1}{c}{ Family } & \multicolumn{1}{c}{ Genus } & \multicolumn{1}{c}{ Spesies } \\
\hline Anysomyaria & Pinnacea & Pinnidae & Pinna & Pinna muricatta \\
\hline Eulamellibranchia & Carditacea & Carditacea & Trachycardium & Trachycardium rugosum \\
\hline & & & Fragum & Fragum unedo \\
\hline & Mactracea & Mactridae & Mactra & Mactra violacea \\
\hline & Tellinacea & Tellinidae & Tellina & Tellina spengleri \\
& & & Tellina timorensis \\
\hline & Veneracea & Veneracea & Gafrarium & Gafrarium tumidum \\
& & Meretrix & Meretrix Linnaeus \\
\hline
\end{tabular}

Bivalvia yang hidup di daerah perairan Dusun Tanjung Metiella walaupun hanya memiliki substrat dasar perairan yang berpasir bercampur dengan pecahan karang mati dan banyak juga daerah lamun dan alga, namun bivalvia mampu beradaptasi dengan lingkungan tersebut. Selain kondisi perairan pantai yang demikian mampu mendukung kelangsungan kehidupan bivalvia, selain itu parameter lingkungan

Kepadatan rata-rata Bivalvia yang ditemukan pada Perairan Dusun Tanjung Metiella dapat dilihat pada tabel 3 dibawah ini: 
Tabel 3. Nilai Kepadatan Bivalvia di Perairan Dusun Tanjung Metiella

\begin{tabular}{|c|c|c|c|c|c|c|c|}
\hline \multirow{2}{*}{ No } & \multirow{2}{*}{ Jenis Bivalvia } & \multicolumn{5}{|c|}{ Kepadatan ind $/ \mathrm{m}^{2}$} & \multirow{2}{*}{ Tota } \\
\hline & & TI & TII & TIII & TIV & TV & \\
\hline 1 & Fragum unedo & 4,6 & 5,8 & 4,2 & 4,2 & 3,4 & 22,2 \\
\hline 2 & Trachycardium rugosum & 3,4 & 2,2 & 1,6 & 0,6 & 0,6 & 8,4 \\
\hline 3 & Mactra violacea & 1 & - & 0,2 & 1 & 1,2 & 3,4 \\
\hline 4 & Tellina spengleri & 1 & 2,2 & 2 & 1,2 & 1,4 & 7,8 \\
\hline 5 & Tellina timorensis & 1,8 & 1 & 1,8 & 0,6 & 0,4 & 5,4 \\
\hline 6 & Pinna muricata & 0,8 & 0,4 & 0,4 & 1 & 0,8 & 3,4 \\
\hline 7 & Gafrarium tumidium & 1,2 & 1,6 & 0,4 & - & - & 3,2 \\
\hline 8 & Meretrix Linnaeus & 0,4 & 1,4 & - & 0,6 & - & 2,4 \\
\hline & TOTAL & 14,2 & 14,4 & 10,6 & 9,2 & 7,8 & 56,2 \\
\hline
\end{tabular}

Hasil dari tabel 3 di atas memperlihatkan bahwa, nilai kepadatan tertinggi pada transek I dimiliki oleh spesies Fragum unedo dengan nilai sebesar 4,6 ind $/ \mathrm{m}^{2}$, sedangkan nilai kepadatan terkecil atau terendah dimiliki oleh spesies Meretrix Linnaeus dengan nilai kepadatan 0,4 ind $/ \mathrm{m}^{2}$. Pada transek II, nilai kepadatan tertinggi dimiliki oleh spesies Fragum unedo dengan nilai sebesar $5,8 \mathrm{ind} / \mathrm{m}^{2}$, sedangkan nilai kepadatan terendah dimiliki oleh spesies Pinna muricata dengan nilai kepadatan $0,4 \mathrm{ind} / \mathrm{m}^{2}$. Pada transek III nilai kepadatan tertinggi dimiliki oleh spesies Fragum unedo dengan nilai kepadatan sebesar 4,2 ind $/ \mathrm{m}^{2}$, sedangkan nilai kepadatan terkecil atau terendah dimiliki oleh spesies Mactra violacea dengan nilai kepadatan sebesar 0,2 ind $/ \mathrm{m}^{2}$. Pada transek IV nilai kepadatan tertinggi dimiliki oleh spesies Fragum unedo dengan nilai kepadatan sebesar $4,2 \mathrm{ind} / \mathrm{m}^{2}$, sedangkan nilai kepadatan terkecil atau terendah dimiliki oleh spesies Trachycardium rugosum, Tellina timorensis dan Meretrix Linnaeus dengan nilai kepadatan sebesar $0,6 \mathrm{ind} / \mathrm{m}^{2}$. Pada transek V nilai kepadatan tertinggi dimiliki oleh spesies Fragum unedo dengan nilai kepadatan sebesar $3,4 \mathrm{ind} / \mathrm{m}^{2}$, sedangkan nilai kepadatan terkecil atau terendah dimiliki oleh spesies Tellina timorensis dengan nilai kepadatan sebesar $0,4 \mathrm{ind} / \mathrm{m}^{2}$.

Berdasarkan nilai kepadatan di Perairan Dusun Tanjung Metiella Negeri Liang Kecamatan Salahutu Kabupaten Maluku Tengah ternyata spesies Fragum unedo mendominasi lokasi penelitian dimana factor utama yang mendukung keberadaan spesies ini adalah kecocokan habitat sehingga jumlah individu yang diperoleh sangat besar (Sopamena,2010). Selain itu faktor pendukung lain yang menyebabkan tinggi rendahnya nilai kepadatan suatu spesies yaitu pasang surut, arus dan lainnya (Nybakken, 1992 dalam Sopamena 2010).

\section{KESIMPULAN}

Berdasarkan hasil penelitian yang diperoleh maka didapatkan beberapa kesimpulan sebagai berikut:

1. Di perairan Dusun Tanjung Metiella ditemukan 8 jenis Bivalvia yaitu: Fragum unedo, trachycardium rugosum, Mactra violacea, Tellina spengleri, Tellina timorensis, Pinna muricata, Gafrarium tumidum dan Meretrix linnaeus.

2. Nilai kepadatan tertinggi terdapat pada transek II dengan nilai kepadatan sebesar $5,8 \mathrm{ind} / \mathrm{m}^{2}$ ditemukan pada jenis Fragum unedo dan nilai kepadatan terendah terdapat pada transek III dengan nilai kepadatan sebesar $0,2 \mathrm{ind} / \mathrm{m}^{2}$ ditemukan pada Mactra violacea.

\section{DAFTAR PUSTAKA}

Alfiansyah A (2014), Struktur Komunitas Bivalvia Pada Kawasan Padang Lamun Di Perairan Teluk Dalam, E, Jurnal (diakses 13 Februari 2017)

Baharessa, F. 2002. Studi Kepadatan dan Distribusi Bivalvia (Polymesoda sp) Pada Daerah Hutan Mangrove di Teluk Kendari. Skripsi. Kendari. 
Dahuri, R. 2003. Keanekaragaman Hayati Laut, Potensi Keberlanjutan Sumberdaya di Indonesia. Djambatan, Jakarta.

Dahuri, R., J. Rais., S.P. Ginting., dan Cahyani. 1992. Pengelolaan Sumer Daya Wilayah Pesisisr dan Lautan Secara terpadu. Cetakan Kedua. Pradnya Paramita. Jakarta

Dharma, Bunjamin. 1988. Siput dan Kerang Indonesia (Indonesia Shells). PT. Sarana Graha, Jakarta.

Herman, N. D. 2001. Struktur Komunitas Makrobenthos Pada Perairan Intertidal Tanjung Tiram Kecamatan Moramo. Skripsi. Unpatti. Ambon.

Hutabarat, S. E dan M. Evans, 1984. Pengantar Oseanografi. Penerbit Universitas Indonesia (Press). Jakarta.

Khouw, A. S. 2008. Metode dan Analisis Kuantitatif Dalam Bioekologi Laut

Latumeten, J. 2003.Suatu Kajian Tentang Pengelolaan Sumberdaya Ikan di Perairan Provionsi Maluku. Makalah Pada Forum Koordoinasi Pengelolaan Potensi Sumberdaya Ikan. Ambon.

Meglitsch, P.A. 1972. Invertebrata Zoology. Oxford University Press. London

Nontji, A. 1987. Laut Nusantara. Penerbit Djambatan. Jakarta
Nybakken, J. 1992. Biologi Laut: Suatu Pendekatan Ekologis. PT. Gramedia Jakarta

Russel - Hunter, W. D. 1983. The Mollusca. Ekologi. Vol. 6. Academic Press New York.

Romimohtarto, K dan S, Juwana. 2001. Biologi Laut: IImu Pengetahuan Tentang Biologi Laut. Penerbit Djambatan. Jakarta

Soegianto, A. 1994. Ekologi Kuantitatif. Metode Analisis Populasi dan Komunitas. Penerbit Usaha Nasional. Surabaya-Indonesia.

Tarigan MS, Edward. 2003. Kondisi Hidrologi Perairan Teluk Kao, Pulau Halmahera Maluku Utara. Pesisir dan Pantai Indonesia. 8: 19-23

Tomascik, T. Ammarie, Nontji. A dan Muhamad K. M. 1997. The Ecology of the Indonesia Seas, Part Two Periplus Edition.

Salampessy, J. 2016. Struktur Komunitas Bivalvia Di Daerah Intertidal Pantai Waru Putih Desa Kabauw Kecamatan Haruku Kabupaten Maluku Tengah. Skripsi. Ambon.(Tidak dipublikasikan).

Sumaali, S. 2013.Struktur Komunitas Bivalvia Di Daerah Intertidal Pantai Batu LubangKabupaten Seram Bagian Barat. Skripsi. Ambon (Tidak dipublikasisskan). 